\title{
Artigo
}

\section{NO BALÉ E NO TEATRO: A FAMÍLIA COMO MEDIAÇÃO NA FORMAÇÃO DO PROFESSOR-ESPECTADOR}

\section{BALLET AND THEATRE: FAMILY AS MEDIATION IN THE TEACHER-SPECTATOR'S TRAINING}

ENEL BALLET Y EN EL TEATRO: LA FAMILIA COMO MEDIADORA EN LA FORMACIÓN DEL MAESTRO-ESPECTADOR

Taís Ferreira

Professora adjunta no curso de teatro da Universidade Federal de Pelotas, nas áreas de História do Teatro e de Pedagogia das Artes Cênicas. 


\section{Resumo}

Esse artigo apresenta, a partir de exemplos localizados de experiências de dois professores de teatro e dança brasileiros, considerações sobre a relação entre a formação de uma identidade de espectador e a mediação da família nesse processo constitutivo, a partir das primeiras memórias dos professores como espectadores. Alicerçando a discussão, são evocados conceitos seminais da obra bourdiana como de capital cultural e simbólico e habitus, além da concepção da memória trazida pelo neurocientista Iván Izquierdo. A partir das pistas apresentadas, concluo com uma sugestão para a formação docente em artes cênicas.

Palavras-chave: Espectador, Família, Formação docente, Artes Cênicas.

\section{Abstract}

This article presents, based on the experiences of two Brazilian teachers of theatre and dance, considerations about the relationship between the constitution of a spectator's identity and the family's mediation in this process according to the teachers' first memories as spectators. To corroborate this discussion, seminal concepts by Pierre Bourdieu were used, such as the cultural and symbolic capital and habitus, as well as the conception of memory by the neuroscientist Iván Izquierdo. From the subject presented, I finished suggesting the training of performing arts' teachers. Keywords: Spectator, Family, Teachers' training, Performing arts.

\section{Resumen}

Este artículo presenta, a partir de experiencias de dos maestros brasileños de teatro y danza, consideraciones sobre la relación entre la formación de una identidad de espectador y la mediación familiar en este proceso constitutivo, desde los primeros recuerdos de los maestros como espectadores. En la discusión se utilizan conceptos seminales de la obra de Pierre Bourdieu como capital cultural y simbólico y habitus, además de la concepción de memoria presentada por el neurocientifico Iván Izquierdo. $Y$ desde lo presentado, sugiero que debe haber una formación para maestros en las artes escénicas.

Palabras clave: Espectador, Familia, Formación docente, Artes escénicas. 


\section{Introdução: famílias e memórias}

Este artigo relaciona memórias de um professor de teatro e de uma professora de dança como espectadores com a mediação familiar. Os dados e as análises apresentados são provenientes de um primeiro olhar sobre material empírico construído por meio de um questionário que foi respondido por 95 professores de teatro e dança sobre suas experiências e formações como espectadores.

Esta análise foi tecida a partir das respostas a questões que podem nos remeter diretamente à articulação entre formação de espectadores, escola, família e experiências, mediações essas já apontadas em pesquisas anteriores realizadas por mim. As respostas que serão analisadas foram dadas às perguntas: "Qual a primeira lembrança (ou mais remota) que tens de ti como espectador/a? Quando e onde foi? Qual a situação? Quem estava contigo? O que foi assistido?." Emerge com proeminência a família como mediadora da relação dos professores enquanto espectadores em suas primeiras memórias.

Conforme Iván Izquierdo (2013, p. 18), em palestra proferida sobre o tema da memória, "o aspecto mais saliente da memória é o esquecimento". Destarte, posso depreender que aquilo que foi colocado em evidência nas respostas dos professores é o resultado do esquecimento (ou silenciamento) de tantas e tantas outras situações, acontecimentos e experiências. "O que me lembro da tarde de ontem? Muito pouco. O que me lembro da minha infância? Coisas que eu posso relatar em poucas horas" (3lbid., p. 17).

Não podemos deixar de perceber que aquilo que é relatado pelos depoentes na pesquisa faz emergir linhas diretas de conexão com o presente desses professores-artistas, com suas realidades atuais como profissionais das artes e da educação. É na tênue linha entre as primeiras memórias dos depoentes como espectadores, apresentadas a mim, e suas identidades contemporâneas de professores, artistas e espectadores, que desenvolverei a presente análise.

Conforme pesquisa anterior, um estudo de recepção com crianças espectadoras, três foram as mediações preferenciais a atravessar as relações construídas por um grupo de meninos e meninas de classe média, entre os 5 e os 11 anos de idade, com a linguagem teatral: a escola, a mídia e a fa- 
mília. Se pensarmos na intensidade com que essas mediações fizeram-se presentes naquele escopo analítico, a presença da mídia sobrepõe-se à da escola nas narrativas que envolvem construções de significados e sentidos acerca da linguagem teatral. No entanto, a escola aparece como cenário e comunidade de apropriação primeva do teatro. A família também se apresenta como comunidade de interpretação, contudo, nesse caso, de modo menos incisivo do que as outras duas mediações citadas. Ao analisar respostas dos professores que remetem, no geral, à infância ou à juventude dos sujeitos, podemos traçar paralelos com a pesquisa empírica realizada junto ao público de crianças em 2003.

Comentarei, a partir da análise das falas de dois depoentes, lembranças das primeiras experiências de recepção narradas por eles que evocaram a mediação familiar, ou seja, escolhidas pela construção das memórias pessoais desses sujeitos relacionadas às suas famílias. Justifico esse comentário a partir da necessidade de explorar espaços de aprendizagem e apropriação cultural outros, para além da educação formal recebida pelas instituições de ensino (escola, academias de arte, universidade).

Levando em conta a importância conferida à família nas narrativas infantis sobre suas relações com a linguagem cênica, começo a olhar para o material gerado pelos professores me apropriando também das lentes de Bourdieu e pensando na importância da família nas escolhas e construções identitárias dos professores de teatro e dança como espectadores.

\section{Duas famílias: uma professora de dança e um professor de teatro}

A presença da família como mediadora é uma constante que aparece em grande parte das respostas e que parece ter muita força nas primeiras memórias dos depoentes como espectadores. Ao cotejar com as respostas das crianças, por exemplo, vemos que no grupo de professores de teatro e dança a família é uma mediação de maior importância.

Se os estudos culturais latino-americanos apresentam a família como uma das mediações possíveis às relações dos sujeitos com os artefatos culturais e suas potenciais constituições identitárias, o peso conferido por Bour- 
dieu à família em suas investigações sociológicas se sobreporia até àquele conferido pelos estudos culturais, no sentido de que a família seria o núcleo primário da constituição de um habitus ao qual o sujeito, sua visão de mundo, seus valores, hábitos e seu capital simbólico estariam associados. Cumpre notar que o conceito de habitus não confere supremacia nem às estruturas sociais sobre os sujeitos e tampouco dos sujeitos sobre as estruturas, e, sim, opera no registro das trocas e aquisições de capital simbólico associado às práticas da vida cotidiana, dos contextos que atravessam os sujeitos e que por eles são atravessados.

Se considerarmos capital simbólico e habitus nas constituições dos professores, podemos levantar dois casos específicos em que parentes próximos dos depoentes estavam diretamente envolvidos com espetáculos das artes cênicas, como nas narrativas comentadas a seguir. Para Álvaro Rosacosta e Eleonora Santos ${ }^{1}$, a presença das artes cênicas em suas vidas relacionava-se tanto ao cotidiano como ao círculo de convivência familiar, assim como às escolas (de educação infantil e de dança, respectivamente) que frequentavam.

Bourdieu, no seminal estudo sociológico intitulado $A$ distinção - crítica social do julgamento (2006), relaciona a aquisição de competência cultural, ou seja, de ferramentas para se relacionar com determinado artefato da cultura (seja ele artístico ou não), à fusão de conhecimentos e experiências adquiridos conjuntamente em duas instâncias: na família (em primeiro lugar) e na escola (em seguida). Ainda que todas as conclusões que Bourdieu apresenta apontem para a categoria "classe social" como a maior definidora do gosto como elemento de distinção justamente classista, há indícios que aqui nos são caros ao apresentarem a mobilidade de aquisição de competência cultural associada também à educação formal, para além da aquisição determinante de conhecimentos, práticas e experiências de capital simbólico propiciadas pela família.

A citação abaixo justifica essa intrincada relação, antes de procedermos às análises dos relatos dos depoentes:

1. Aos depoentes foi dada a escolha de como gostariam de ter seus nomes referenciados ao longo do trabalho de pesquisa. Aqueles que optaram por permitir o uso de seus próprios nomes (artísticos no geral) estão aqui referidos normalmente, caso de Álvaro e Eleonora. 
Conhecendo a relação que, pelo fato da lógica da transmissão do capital cultural e do funcionamento do sistema escolar, estabelece-se entre o capital cultural herdado da família e o capital escolar, seria impossível imputar unicamente à ação do sistema escolar [...] a forte correlação observada entre a competência em matéria de música ou pintura [...] e o capital escolar: de fato este capital é o produto garantido dos efeitos acumulados da transmissão cultural assegurada pela família e da transmissão cultural assegurada pela escola (cuja eficácia depende da importância do capital cultural diretamente herdado da família). (BOURDIEU, 2006, p. 27)

Sigamos, agora, com as narrativas dos docentes-artistas. A professora de dança Eleonora Santos comenta sua primeira lembrança como espectadora ligada à mãe, que auxiliava nos bastidores de um espetáculo encenado por uma escola de dança:

Foi assistindo ao espetáculo La fille mal gardeé, montado pela escola de balé Dicléa Ferreira de Souza, em Rio Grande. Fui acompanhando minha mãe que foi ajudar nos bastidores do espetáculo. (Eleonora Santos, 2013)

Eleonora estudou balé clássico desde a infância, foi professora em escolas particulares, em escolas técnicas de dança e hoje é professora na licenciatura em Dança da Universidade Federal de Pelotas (UFPel). Sua lembrança mais remota como espectadora está ligada a um percurso profissional construído ao longo da vida como bailarina e professora de balé clássico. $\mathrm{Na}$ fotografia a seguir, Eleonora é a jovem professora de balé de uma turma infantil da mesma escola que menciona em sua primeira lembrança como espectadora, na qual também foi aluna por muitos anos.

Assim, se levarmos em conta as considerações de Izquierdo (2013), a primeira lembrança de si como espectadora está aliada aos laços afetivos e profissionais da professora com uma escola de dança específica, uma determinada modalidade de dança (o balé clássico) e à ligação íntima também de sua mãe com o universo da dança clássica ocidental. A memória de Eleonora reconstrói uma situação (a apresentação de La fille mal gardée na cidade de Rio Grande, RS) que tem um elo direto com suas escolhas profissionais e a presença da família. Possivelmente outras experiências façam parte do 
escopo do "esquecimento", também tratado por Izquierdo, por não terem reverberado de tal modo na constituição identitária e subjetiva da entrevistada.

Figura 1- Turma da Escola de Balé Dicléa, em Pelotas, $1992^{2}$

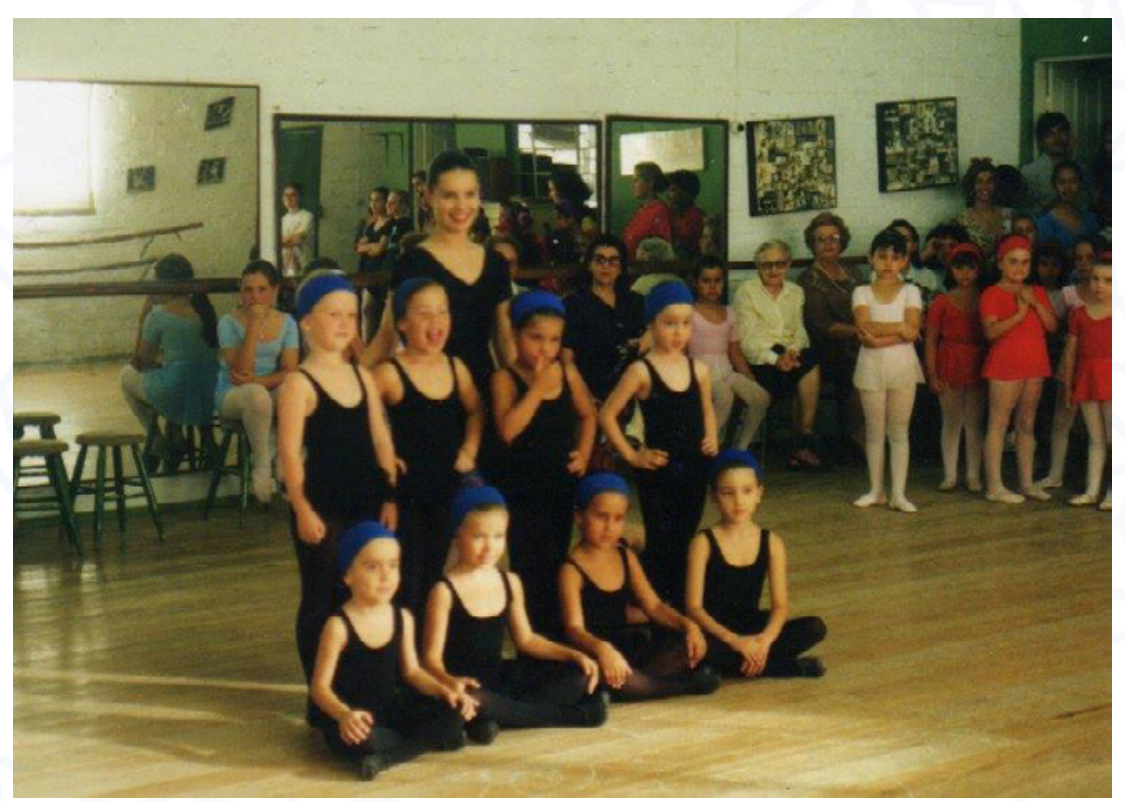

Figura 2 - Eleonora no camarim do espetáculo Sylvia, com a filha Beatriz. A montagem aconteceu no ano de 2012, pela Escola de Balé Dicléa Ferreira, em Pelotas. As duas participaram como bailarinas; Beatriz estuda balé na mesma escola citada nas narrativas da mãe

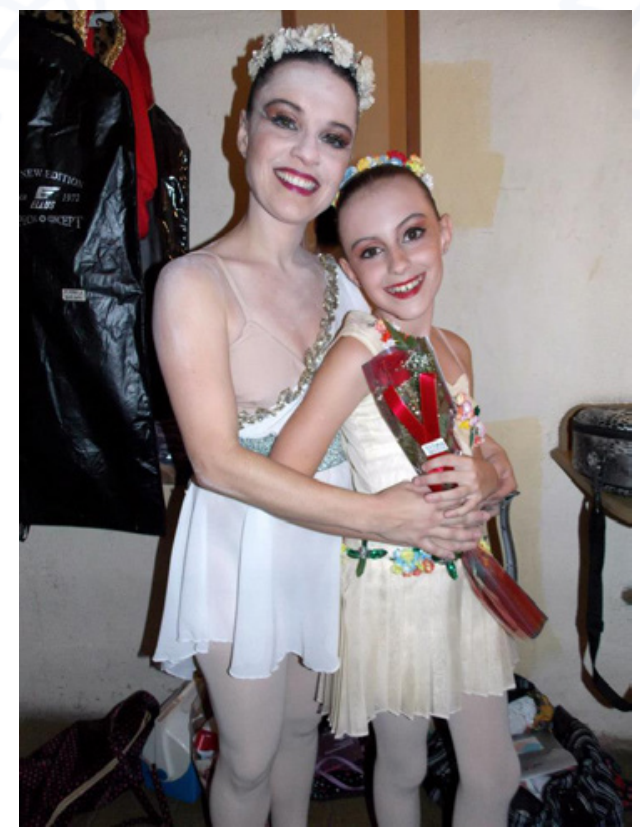

2. As fotografias apresentadas na seção pertencem ao arquivo pessoal dos depoentes e seu uso foi autorizado pelos mesmos para esta pesquisa. 
Figura 3 - Em 2014, Beatriz, Eleonora e Zulce: três gerações participam do Festival de Dança de Joinville

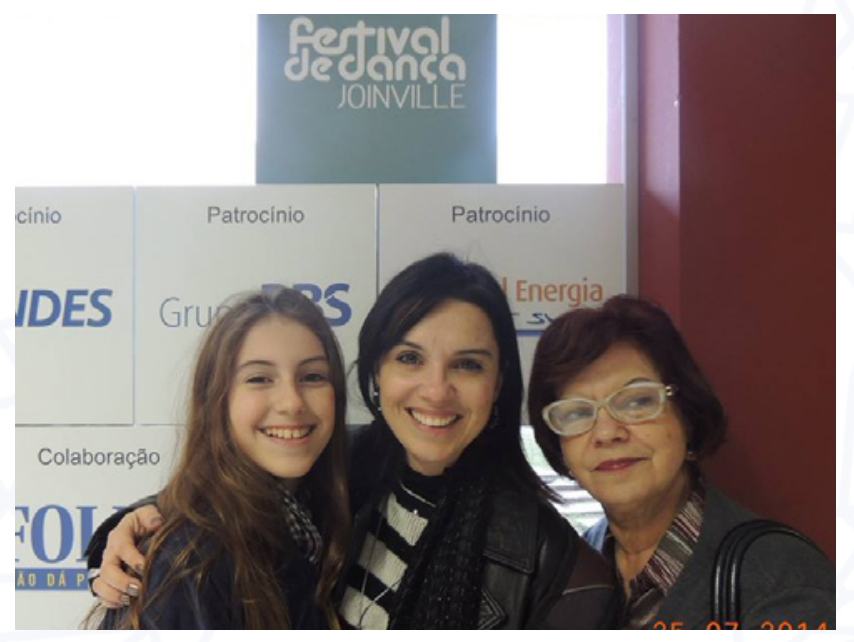

Em depoimento a $\mathrm{mim}^{3}$, Eleonora comenta que a mãe Zulce Motta foi aluna da primeira turma de balé da escola e que a acompanhou, a ela e à filha, mais de uma vez ao Festival de Dança de Joinville ${ }^{4}$, uma prática com a qual a família está há anos envolvida.

Na primeira vez que fui a Joinville, em 1987 (eu tinha 10 anos), minha mãe foi naquela função de acompanhar e tudo mais... depois, no $X$ festival, eu fui e ela foi novamente... e agora lá foi ela me ajudar com a Bia e aproveitar também. (Eleonora Santos, 2013)

Eleonora comenta o interesse que Beatriz, a filha, demonstrou nos debates sobre dança de rua, que foi a temática do seminário do festival no referido ano, e do espanto positivo da mãe, Zulce, ao deparar com as falas de críticos, profissionais e acadêmicos sobre dança, que ela considerou muito mais aprofundadas que no passado. $O$ interesse de Beatriz pela dança de rua, narrado pela mãe Eleonora, demonstra que a competência cultural herdada da família, levantada pelas teorias bourdianas, também confere a possibilidade para a menina de 11 anos de se interessar por outras modalidades

3. Procurei Eleonora Santos por meio de uma rede social para solicitar mais informações, e mantivemos uma conversa através do chat da rede, que foi posteriormente gravada com a permissão da depoente. Já Álvaro Rosacosta foi procurado por mim na mesma rede social e mantivemos contato por e-mail e pelo chat da rede. Ambos autorizaram o uso das fotografias de seus arquivos pessoais e das conversas complementares na pesquisa.

4. Um dos mais importantes festivais de dança do país, que acontece anualmente na cidade de Joinville (SC). 
de dança que não o balé clássico, tão presente em suas relações familiares e na história de vida das mulheres dessa família.

À maneira de Eleonora, o ator, músico e professor Álvaro Rosacosta, remete-nos à sua tenra infância e a um emaranhado de relações entre escolarização, arte e família. Ele nos conta sobre quando assistia a trechos de espetáculos com os pais no tradicional Theatro São Pedro de Porto Alegre, onde membros de sua família trabalhavam e viviam. Nesse caso, a família é altamente significativa, tanto naquilo que é evocado pela memória, como na relação direta com a profissionalização e constituição do sujeito, ou seja, com seu capital cultural e simbólico.

Álvaro, ao relatar sua mais remota lembrança como espectador, nos traz referências afetivas e espaciais concretas: um menino muito pequeno, o palco e a plateia de um teatro, o aconchego do colo dos pais. A cena é terna e demonstra a relação de hábito, de costume, de intimidade da criança pequena e de sua família com o acontecimento cênico e com o edifício teatral. $O$ teatro acolhe os pais e permite ao menino circular e brincar e contar com o conforto e carinho deles. Esse teatro, que para tantos é tão somente um aparelho cultural, um imponente edifício histórico, para Álvaro é a memória do afeto, do jogo, da família e da criança que foi.

Eu descendo do palco do Theatro São Pedro (onde eu morava) e indo para o colo de meus pais ver o final da encenação. (Álvaro Rosacosta, 2013)

Álvaro é ator e musicista, embora tenha se graduado em Artes Visuais na Universidade Federal do Rio Grande do Sul (UFRGS) - começou a estudar artes plásticas na Escolinha de Arte instalada no Theatro São Pedro. É um dos nomes mais significativos do teatro gaúcho de sua geração, participou de muitos elencos em montagens com diferentes grupos e com os principais diretores de Porto Alegre, sendo um dos mais atuantes artistas na Companhia Teatro Novo, conhecida pelas suas encenações voltadas para crianças há mais de 40 anos. É também compositor de muitas trilhas sonoras de espetáculos.

O trabalho pedagógico desenvolvido por Álvaro é o de instrutor de oficinas e workshops. É importante frisar que esse artista porto-alegrense descende de 
uma linhagem de trabalhadores ligados às artes: seu avô foi funcionário do Theatro São Pedro, no qual sua família viveu, e onde ele nasceu e cresceu. A trajetória desse artista foi atravessada por inúmeras experiências vivenciadas dentro do principal aparelho cultural e casa de espetáculos do estado do Rio Grande do Sul.

$\mathrm{Na}$ narrativa abaixo, Álvaro relaciona jocosamente as memórias do teatro, da família e da escola. Mais uma vez, casa, conforto e intimidade estão presentes nas memórias do ator com o teatro.

Só sei que a minha história no palco já começou mal! [risos]. Meu jardim de infância resolveu montar um auto de Natal e apresentar no Theatro São Pedro! Durante os ensaios eu fugia e ia para "casa». Claro que na estreia, eu era o Rei Mago negro (Baltazar?), eu vi os meus pais na plateia e não tive dúvidas: desci pelo meio do palco (naquele tempo existia uma passarela dividindo a plateia) e fui sentar no colo do meu pai para assistir o resto da confusão. [risos]. Minha quase estreia foi em «casa»! [risos]. (Álvaro Rosacosta, 2013)

Figura 4 - O avô Manuel, zelador do Theatro São Pedro a partir de 1949, posa em frente ao teatro

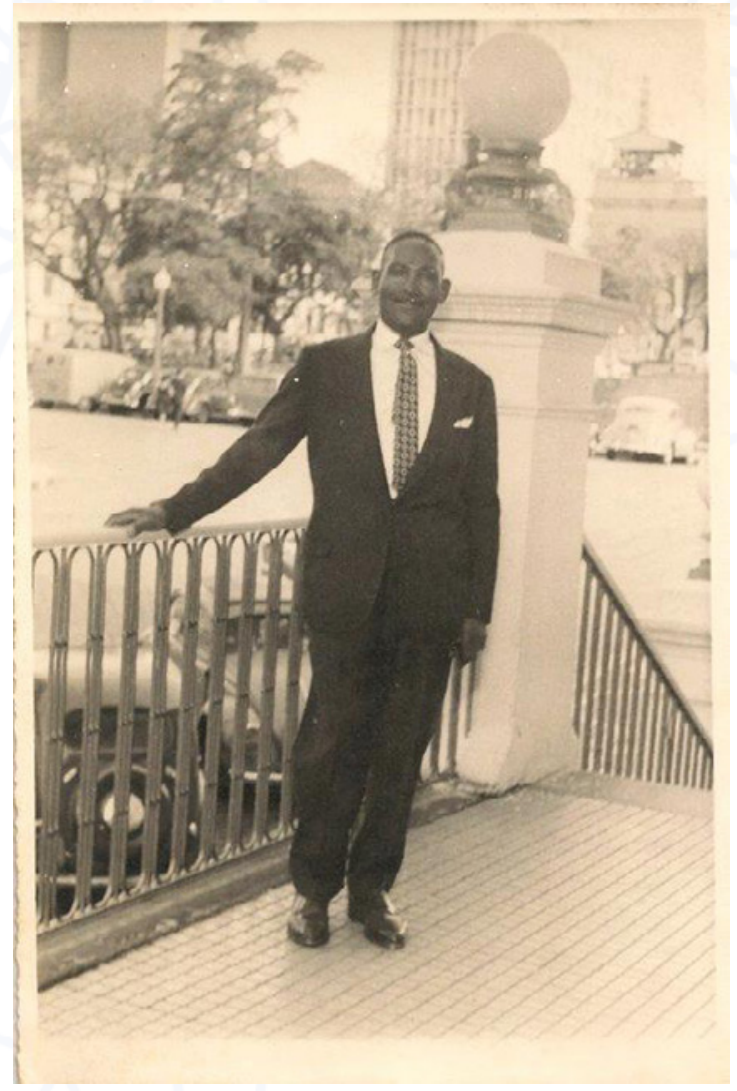


Figura 5 - Álvaro com os pais, no pátio do Theatro São Pedro, onde ficava a casa da família

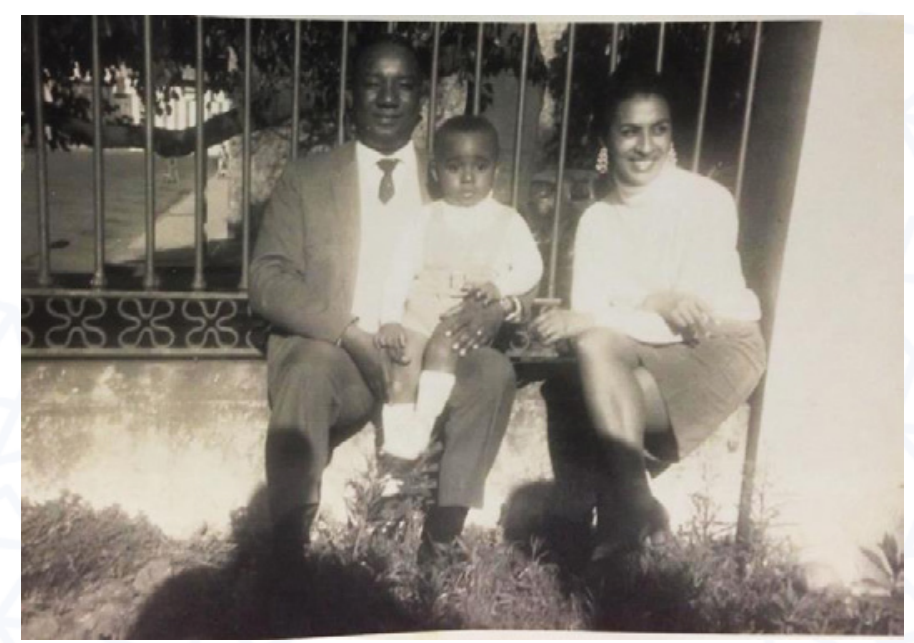

Podemos depreender que as memórias evocadas estão diretamente ligadas a um círculo produtivo relacionado ao presente de cada um desses professores de artes cênicas e reconhecer que a emergência das memórias familiares ressignifica o vivido no passado nas construções identitárias do presente dos docentes. Os depoimentos de Eleonora e Álvaro, apesar de sucintos, são contundentes e mostram como as práticas artísticas promovidas pela família e os contextos familiares podem influir na escolha por determinado campo profissional, na aquisição de capital simbólico, nos atravessamentos constitutivos de um habitus específico.

Todavia, cumpre notar que são comuns os relatos de artistas ou professores de artes em formação que não foram apoiados por suas famílias ao escolherem uma carreira mercadológica e socialmente desvalorizada relacionada aos campos da educação e da arte, nesse caso aos dois, ambos os campos profissionalmente desvalorizados no Brasil. Há duas faces do atravessamento familiar nas escolhas e nas formações identitárias dos docentes-artistas: se por um lado podemos relatar os percursos afetivos e familiares de Eleonora e Álvaro em suas relações com a dança e o teatro, por outro, sabemos que há preconceitos e dificuldades enfrentados tanto pelos que escolhem a carreira artística como pelos que escolhem a carreira docente. Ambas as profissões no país sofrem com baixa remuneração, falta de reconhecimento e instabilidade profissional. 


\section{Algumas colocações derradeiras sobre o tema e uma proposição final}

É importante dimensionar como as primeiras lembranças de professores de teatro e dança como espectadores estão fortemente vinculadas à sua família, o que possivelmente demonstra que contataram pessoas interessadas de alguma forma nas artes da cena, que propiciaram a eles quando crianças e jovens a vivência de determinadas experiências como espectadores.

Dentre 95 depoentes da pesquisa que ora realizo, 50\% citam a família em geral ou algum familiar específico (pai, mãe, avós, madrinha, irmãos, tios, sobrinhos) presente em suas primeiras experiências como espectadores, o que suas memórias trazem como "a mais remota lembrança".

É possível relacionar esses dados e a leitura feita a partir deles ao conceito de capital cultural de Pierre Bourdieu. A aquisição de capital cultural (e de competência para adquirir esse capital) se daria basicamente por duas formas: por meio da herança familiar e do habitus vivenciado pelos sujeitos e por meio da instituição promotora do acesso universal e democrático aos conhecimentos e valores, ou seja, a escola. No entanto, ele traça diferenciações concretas (através de longa exposição de dados empíricos) acerca de como essas constituições de capital cultural e simbólico se dão na sociedade capitalista e como deflagram lutas simbólicas pela aquisição desse capital, que acaba sendo o grande legitimador das classes.

Não nos interessa aqui, propriamente, a discussão de caráter classista empreendida por Bourdieu e que atravessa a base de toda sua obra. Contudo, interessa-nos pensar em como, de modo significativo, podemos traçar relações entre um capital simbólico vinculado à herança familiar e as narrativas de constituição como espectadores dos professores, isso em um momento sócio-histórico de amplas e irreversíveis transformações, principalmente naquilo que concerne ao acesso a esses bens simbólicos. Parece-me que no caso das artes da cena, por mais que tenhamos na mídia inúmeras demonstrações de possíveis leituras e vivências com essas linguagens, é por meio da família e da escola, instâncias que medeiam a aquisição de capital e competência culturais dos professores, que o acesso a esses bens se efetiva. 
Gostaria de finalizar essas considerações sobre formação de identidades de espectadores-professores, famílias e memórias, assinalando sugestões de práticas na formação docente em artes cênicas que envolvam a construção mnemônica dos docentes de teatro e dança como espectadores. Ao narrar as suas memórias, ao evocar determinadas lembranças e silenciar outras, os professores, através de suas escolhas, também constroem suas identidades de espectadores. Problematizar essas construções de identidades de espectador (a começar pelas suas próprias) poderia estar na base de uma formação docente em artes cênicas também voltada, de modo consciente e problematizador, às pedagogias do espectador, tantas vezes silenciadas em nossos currículos, projetos pedagógicos e planejamentos de aulas de teatro, dança, performance, ópera, circo.

Portanto, levando em consideração os aspectos abordados que relacionam memória, família e identidade docente, gostaria de propor que as memórias dos professores como espectadores, em suas mais diversas facetas, fossem exploradas nos percursos de formação docente na universidade, tanto nas licenciaturas como nos cursos de especialização docente, de pós-graduação e nas ações de extensão vinculadas à formação continuada de professores, sejam eles específicos de teatro e dança ou pedagogos ou de outras áreas - como no caso da pesquisa "Identidades musicais de alunas de Pedagogia - músicas, memória e mídia" (TORRES, 2003), desenvolvida com o propósito de estudar a constituição de sua identidade docente.

Consequentemente, produzir narrativas (orais, visuais, sonoras, sinestésicas, corporais, lúdicas) vinculadas às nossas memórias como espectadores se colocaria como um instigante ponto de partida para a construção de (im) possíveis e (des)necessárias pedagogias do espectador nas salas de aula universitárias e também naquelas da educação básica e dos cursos livres. Rememoremos, enfim, para, quiçá, sermos.

\section{Referências bibliográficas}

BOURDIEU, P. A distinção: crítica social do julgamento. São Paulo/Porto Alegre: Edusp/Zouk, 2006.

FERREIRA, T. A escola no teatro e o teatro na escola. 2. ed. Porto Alegre: Mediação, 2010. 
IZQUIERDO, I. Conferência de abertura. ISAACSSON, M. et al. (orgs.). Tempos de memória: vestígios, ressonâncias e mutações. Porto Alegre: AGE, 2013.

TORRES, M. C. A. R. Identidades musicais de alunas de Pedagogia: músicas, memória e mídia. 2003. Tese (Doutorado em Educação) - Faculdade de Educação da Universidade Federal do Rio Grande do Sul, Porto Alegre, 2003. Disponível em: <http://www.ufrgs.br/neccso/pdf/tese_identidadesmusicais.pdf>. Acesso em: 28 dez. 2015.

Recebido em 13/01/2016

Aprovado em 04/04/2016

Publicado em 30/06/2016 